\title{
LA IDENTIDAD NARRATIVA EN EL ESPACIO-TIEMPO DE LA REALIDAD VIRTUAL $^{1}$
}

Por:

Andrea Rodríguez Mancera ${ }^{2}$

Profesora de la Universidad Icesi

andrea_rm@hotmail.com

\section{Resumen:}

En "Sí mismo como otro" (1996) Ricoeur describe la identidad-narrativa y dice de ésta que la palabra dada es uno de los elementos que constituyen la historicidad del sujeto. Hoy, gracias a la tecnología y a los avances en informática, en especial los sitios web de redes sociales, el sujeto es representado por el objeto virtual Perfil de Usuario, escenario que despliega un amplio campo de estudio acerca de la comunicación y la construcción de la identidad personal en el ciberespacio. Este artículo expone brevemente, y a modo de introducción en dicha área, la relación entre los objetos virtuales alojados en una realidad virtual: palabra, imagen digital y Perfil de Usuario. El caso seleccionado ha sido el mundo virtual Facebook.com.

Palabras claves: Realidad virtual, simulación, interacción, objeto virtual, perfil de usuario, imagen digital.

\footnotetext{
Abstract:

In "Sí mismo como otro" (1996) Ricoeur describes the narrative - identity and says about it that the given word is one of the elements that constitute the subject's historicity. Today, thanks to technology and IT advances, especially social networking sites, the subject is represented by the virtual object User Profile, stage that unfolds a broad field of study on communications and building of personal identity in the cyberspace. This article shows briefly, as an introduction in that matter, the relationship between the virtual objects of a virtual reality: word, digital image and User Profile. The chosen case is the virtual world in Facebook.com.
}

Key words: Virtual reality, simulation, virtual object, user profile, digital image. 


\section{Introducción}

Mirar a la Gorgona cara a cara es, en el relámpago de su ojo, dejar de ser uno mismo, perder la propia mirada, condenarse a la inmovilidad. Vernat. ${ }^{3}$

Proyección: la vida en tiempo real. Dos filmes estrenados en 2009 desarrollan su trama argumentativa en un punto temático más allá del morphing digital: el de una transformación de los cuerpos y del Yo en los mundos virtuales generados por la realidad virtual. -Canevacci (2003) diría que se trata de los Body-selves, de los múltiples yos que coexisten dentro-fuera del cuerpo-. Una de ellas, Surrogates de Jonathan Mostow, traducida al español como "Identidad Sustituta"; la otra Gamer, dirigida por Mark Neveldine y Brian Taylor.

A pesar de que ambas historias parecen estar inspiradas en la popular red social Second Life y

el juego de estrategia y simulación social The Sims, la segunda centra su eje narrativo en

los videojuegos de séptima generación (Wii, Xbox 360, Playstation 3, Nintendo DS,

Nintendo DSi, PlayStation Portable, Zeebo) y, en ese sentido, los directores han aumentado la velocidad de los fotogramas por segundo para causar la sensación de vértigo visual y auditivo en sintonía con las tecnologías del entretenimiento y su lógica de generación de ambientes virtuales que mantengan al espectador en un estado constante de fascinación, de shock -o de ese estado catártico que no llega a la lucidez del alma-.

Por otra parte, las dos desarrollan su trama en medio de comunidades de la era de la virtualidad digital. Surrogates habla de tres tipos: una comunidad conformada por usuarios que, desde sus habitaciones, teledirigen a sus clones a través de tecnología inalámbrica; otra, la de los clones-sustitutos que remplazan a los seres

humanos tiempo completo en labores cotidianas como trabajar, estudiar y relacionarse en la ciudad; otra más, la de los rebeldes seres humanos que aún consideran su humanidad como el bien más preciado y por tanto no desean adquirir un clon diseñado a imagen y semejanza de los más valiosos y costosos anhelos y deseos: la belleza física y la eterna juventud. Así mismo Gamer describe tres tipos de mundos virtuales en una "ciudad digital”": (1) el de la Society, que es la versión más actualizada de The Sims pero con avatares de carne y hueso: personas que dan en alquiler su cuerpo y su mente para ser virtualmente animados por usuarios que pagan para dirigir; (2) el del mortal juego Slayers en el que los jugadores también son seres humanos que se ofrecen a participar como avatar a cambio de la libertad que les concederá el gobierno estadounidense y su sistema penitencial - j!-

; y (3) el "mundo real" en el que los medios de comunicación y la empresa que diseñó los juegos de simulación obnubilan con fascinantes imágenes publicitarias la mente de los espectadores que invierten su tiempo en la Society dando vía libre a las posibilidades de juego con el cuerpo de otros, o detrás de la pantalla esperando el próximo capítulo de las sanguinarias batallas de los avatares: hombres sin identidad propia pero sensibles al dolor del cuerpo y a la muerte ${ }^{5}$ : 
GINA PARKER: ¿Cómo funciona esto?

Sr. CASTLE: Comienza con una nanocélula implantada en la corteza motora

del cerebro. Esta célula se puede replicar, reemplazando las células con

copias perfectas. Y estas copias contienen acceso remoto de funcionalidad y

forma una compleja red celular llamada "ninex".

PARKER: ¿Es cierto que todo ser humano que se someta a este procedimiento tendrá una dirección IP distinta, como un equipo móvil o una computadora personal?

Sr. CASTLE: Similar, pero el control está estrictamente localizado a los perímetros de nuestro ambiente de juego. Por ejemplo en Society, una vez que nuestros miembros salen de ese mundo, son completamente libres del control y del monitoreo de ese jugador.

El último aspecto en común de estas dos versiones cinematográficas de las relaciones sociales en la era de la RV, es el relacionado con la percepción del placer y la sexualidad. Se trata del clon de Surrogates y del avatar de carne y hueso de Gamer (femenino, joven, y con la imagen hegemónica de belleza que caracteriza a ese mundo virtual del entretenimiento estadounidense): en contraste con la belleza, los usuarios del clon y el avatar son hombres de mediana edad con obesidad mórbida y tendencias bisexuales. En la trama narrativa, este clon y este avatar son conducidos a lugares en los que una masa de clones-avatares de apariencia juvenil, entre licores y alucinógenos, se besan, se tocan y, en el trasfondo de los actores extras, mantienen relaciones sexuales orgiásticas. Aquí, el espacio de la pantalla (electrónica, del cine, de la televisión) se llena de senos, nalgas y sexos de pieles sin vellosidad y cuerpos delgados que limitan con la anorexia. "Lo sexual no es más que un ritual de la transparencia” afirmaba Baudrillard (1988) para concluir que la imaginación erótica y
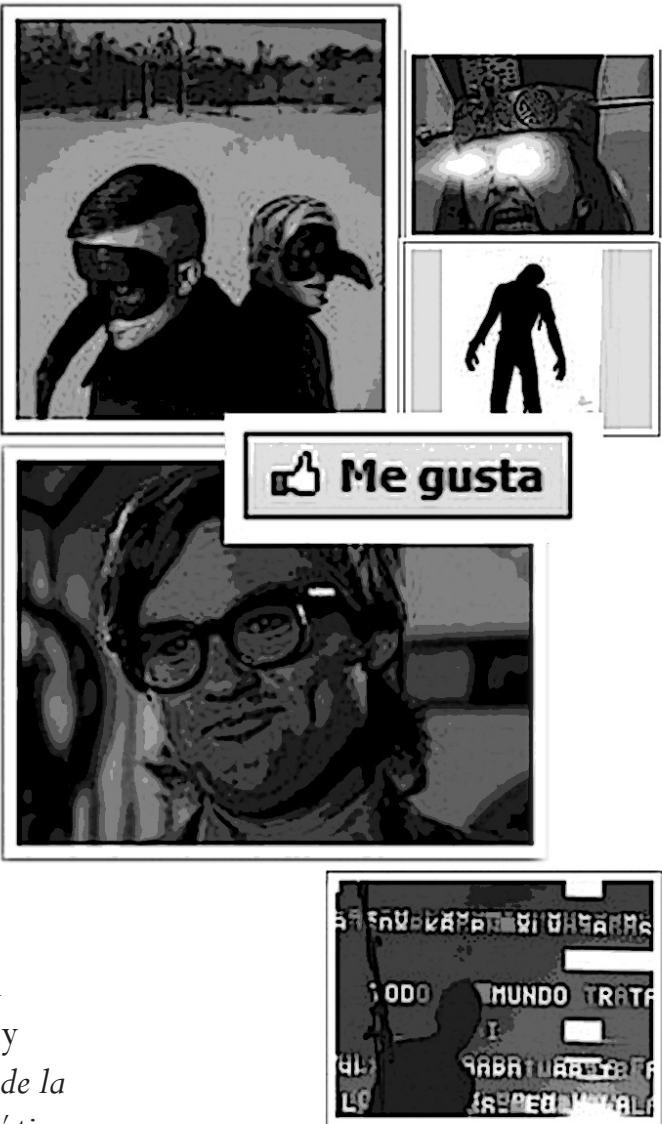

la pornografía dejaron de ser para dar paso a los efectos especiales, a la obscenidad de "lo real"; porque la realidad virtual y el avatar son la fuente de la belleza, de la eterna juventud y de la inmortalidad. El cuerpo vuelve a ser la prisión de la mente.

\section{La prisión de la mente}

Mi propuesta de lectura pretende que usted considere este texto como una serie de apuntes hilvanados para reflexionar acerca de la «identidad-avatar». En primer lugar, revisaremos brevemente las condiciones de los objetos virtuales en una Realidad Virtual [RV]. Para ello tomaremos el caso del objeto virtual Perfil de Usuario de la comunidad Facebook.com. En segundo lugar, abordaremos la idea de la imagen digital de las redes sociales en tanto información de la realidad que opera como referente de la vida offline del Usuario y, además, le ofrece la posibilidad de animar la ficción histórica de su vida con escenas de la vida de sí mismo. Finalmente, ya en tercer lugar, ofreceré algunas pistas que dan sentido a aquello que puede considerarse como la noción, entre comillas angulares, arriba mencionada. 
Este es nuestro primer nodo de ideas:

Las tecnologías de la información, en especial las redes sociales de Internet, ofrecen al usuario la posibilidad de hacer de la historia de su vida una ficción histórica simulando aspectos de la identidad personal que, en el mundo real, no han sido expresados de manera consciente.

\section{Simulación: oda a la creación del universo}

Si mi vida no puede ser aprehendida como una totalidad singular, no podré nunca desear que sea una vida lograda, realizada. Ahora bien, nada en la vida real tiene valor de comienzo narrativo; la memoria se pierde en las brumas de la infancia; mi nacimiento y, con mayor razón, el acto por el que he sido concebido pertenecen más a la historia de los demás, en este caso a la de mis padres, que a mí mismo. Y la muerte, sólo será el final narrado en el relato de los que me sobrevivan; me dirijo siempre hacia la muerte, lo que excluye que yo la aprehenda como fin narrativo. (Ricoeur, 1996:63).

Abrir una cuenta de Facebook es dar nacimiento a una forma de vida, a una animación que se apoya en los datos de la memoria del usuario y deja huella en el software de la red social. En ese sentido, el Perfil de Usuario es una "totalidad singular" ya que es un hipertexto que narra la vida online de esa forma de existencia.En Internet, simular es dar la cualidad de real a un objeto virtual y preferir esa representación del objeto más que a la cosa que existe en "lo real". El concepto «simular» guarda relación con la imaginación y los límites espaciales, así como con la memoria y los estados mentales -en el sentido de Searle-. El simulador de avión fue una de las primeras experiencias de realidad virtual. Para Ivan Sutherland (1968) la «simulación» consistía en un software que permitía modelar matemáticamente una entidad visible en la pantalla del ordenador. De esta manera, operando una máquina que simulaba la sensación de volar, se disminuían los accidentes en los entrenamientos de la fuerza aérea (Wolley, 1994:31-44).

Hoy, manipular objetos virtuales 3D es una tarea cotidiana (por lo menos en los círculos científicos y en el de los individuos de altos ingresos económicos que se

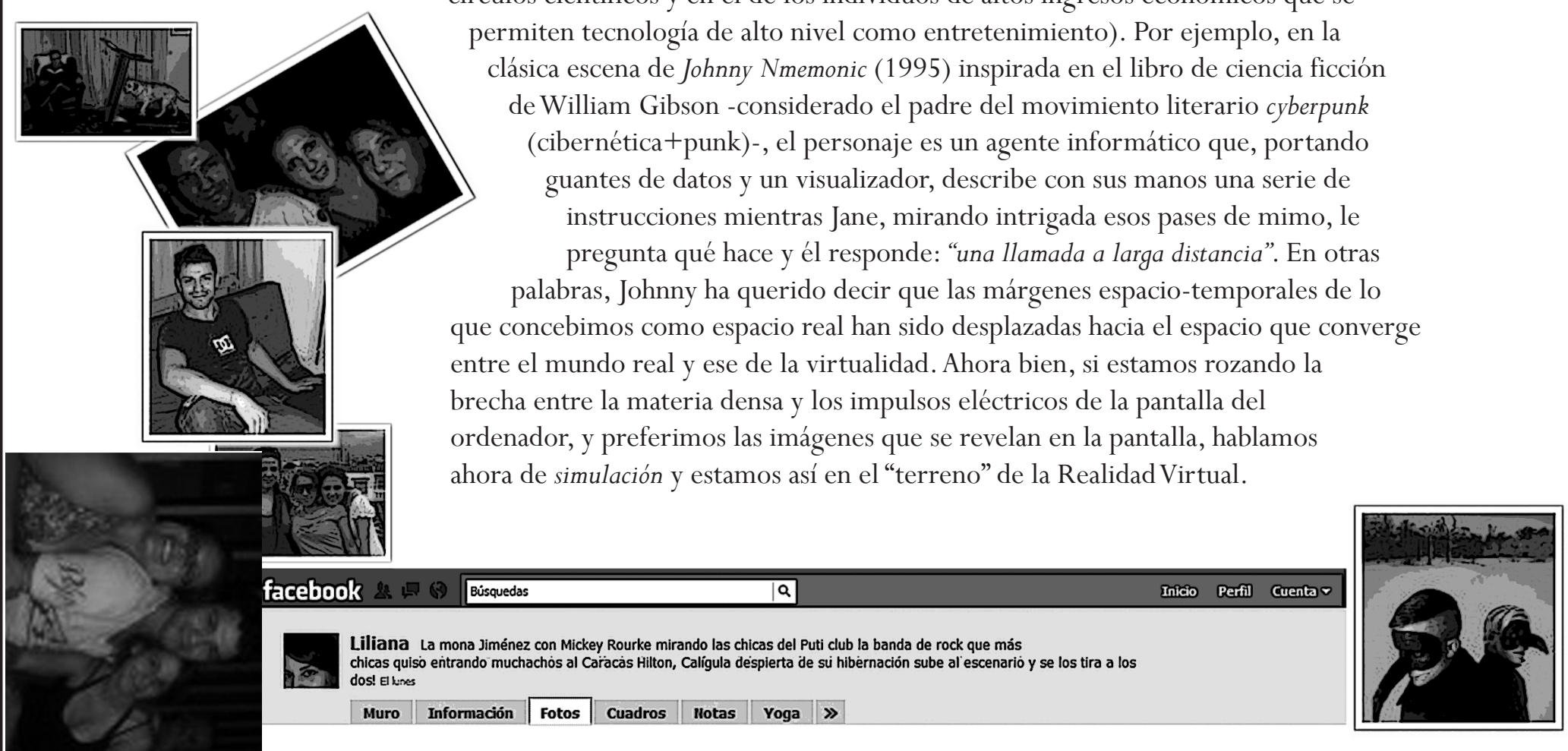


El término «Realidad Virtual» tiene dos acepciones relacionadas entre sí y comúnmente aceptadas en las comunidades científico-comercial y académica: la primera se refiere a la RV como mera herramienta de simulación (la fórmula I ${ }^{3}$ de Grigore Burdea: Inmersión-Interacción-Imaginación) que posibilita al usuario acceder a espacios virtuales digitales. De ahí que cualquier máquina e instrumento de simulación sea clasificado como RV en tanto el usuario interactúa en múltiples interfaces envolventes y manipula los objetos virtuales que se alojan en ese espacio digital, por ejemplo, los diferentes tipos de dispositivos -la mayoría inventados por el Departamento de Defensa de los Estados Unidos- (I) de localización como trajes y Guantes de Datos (o Electroguante) Joysticks 3D, Mouse 3D o Murciélagos, Esferas de Fuerza, Esferas de Rastreo o Track Balls, Rampas, LifeCycles; (II) de generación de imágenes como el Casco de Visualización 3D o HMD, los Sistemas Binoculares o BOOMs, los Lentes Estereoscópicos; (III) de sonido y espacio como la videoconsola de séptima generación de Nintendo, elWII; (IV) de retroalimentación táctil como las pantallas táctiles (touchscreen) tan comunes hoy en día en los cajeros automáticos, las agendas electrónicas, la telefonía celular y los tablets.

El otro sentido del concepto «RV» implica el término «espacio virtual» del cual deriva, y con el favor de la literatura de ciencia ficción, la noción «Ciberespacio». Estos espacios virtuales son los mundos virtuales digitales en los que las multitudes inteligentes operan con objetos sensibles (Rheingold, $2004)^{6}$, o con constructos virtuales si consideramos que los objetos allí alojados son producciones de la mente humana que gusta generar ilusiones y creer en ellas (Maldonado, 2004), o con hiperrealidades en las que las imágenes no representan ya una "realidad profunda”, ni una apariencia sino que corresponden al orden de la simulación (Baudrillard, 1978).

En ese sentido, la palabra es también un objeto virtual pues encierra en sí misma las características de ese tipo de cosas. En los espacios virtuales, la palabra simula una presencia. Es el Caronte de los lectores. El asunto mental de quien se sumerge en ella y experimenta el recorrido virtual por las dimensiones y los detalles presentes.
Pensemos aquí en los términos de uso cotidiano «Inmersión»y «Navegación» cuyo significados marítimos son desplazados en el discurso sobre Internet para referir el comportamiento perceptivo de un sujeto de experiencias que observa una imagen figurativa, o al usuario de Internet que se desplaza en los espacios modelados por ordenador ${ }^{7}$, o al lector atento que bucea entre las descripciones narradas por el autor. El agua, recordemos de pasada, es símbolo de lo inconsciente. Gubern escribía: "La materia prima de la comunicación a través de la red es la escritura, un sistema gráfico que Freud calificó lúcidamente como "la palabra del ausente". (2000:137). Por tanto, la palabra escrita es también una RV en los dos sentidos mencionados: aquí, es herramienta de simulación pues cumple una función simbólica al implicar siempre una característica convencional, una figura simbólica o un signo representante, por analogía o convención, de una idea -pienso sobre este asunto en los jeroglíficos, en los medou-Neter de las épocas del Antiguo Egipto que transmitían una realidad-. Allí, es espacio virtual porque cumple una función imaginaria que opera como reminiscencia (o intuición que podría llamarse a priori), (Miller, 1977:34). pues evoca un complejo de pensamientos al funcionar como dispositivo hipertextual que permite enlazar textos alojados en la red y seguir el hilo que conduce a diversos universos subjetivos ${ }^{8}$.

Los mundos virtuales son insuflados por la palabra escrita. La metamorfosis de los cuerpos nuevos se hizo posible en el sistema de la red informática. Esa RV que es la palabra dada, es la metáfora viva de Ricoeur. Aceptarla así es reconocer la pertinencia semiótico-pragmática de concebir a los seres que habitan esos mundos digitales ya no como objetos simulados que emplean el lenguaje del sistema informático para “comunicarse con la máquina” -he ahí otra metáfora con un nivel superior de abstracción-, sino como entidades creadoras de todas las cosas. La incoherencia metafórica es casi inevitable: la palabra escrita simula la presencia de un ser existente al que se dirige el Usuario cuando escribe en su objeto virtual Perfil de Usuario. 


\title{
4 El objeto virtual Perfil de usuario
}

\author{
- He enviado esta nota a los peces del mar: \\ «Es cuanto más o menos yo puedo desear». \\ Los viles pececitos, a mi urgente misiva, \\ Contestan con lacónica expresión negativa. \\ Esta fue su respuesta a vuelta de correo: \\ «Lo haríamos, señor, de ser capaces, pero...».
}

Antonio Rodríguez de las Heras (2004) discierne los espacios virtuales propios del sueño y la imaginación de los virtuales digitales. Dice de los primeros que son mundos posibles gracias a las "máquinas de memoria" como el libro, las imágenes pictóricas o los montajes teatrales. De los segundos explica que sus cualidades devienen de los «objetos virtuales» que allí se alojan: formas sin materia, estados lógicos producto de combinaciones matemáticas, números 1 y 0 , de las que se puede predicar "tienen partes que residen en varios servidores de Internet", pero pueden, a pesar de ello, encontrarse y presentarse como una unidad. Si sufren alteraciones o se eliminan, se regeneran sin mostrar rastros de la transformación. No digamos que son objetos "eternos e inmortales" pues carecen de vida. Pero son intemporales y ubicuos ya que una vez animados se desplazan de un lugar a otro rompiendo toda ley física que determina a los objetos del aquí real. Al respecto, la palabra como objeto virtual sería, en palabras de Rodríguez de las Heras, la polea del pozo de lo oculto detrás de lo tangible de la pantalla.

Turing revolucionado: patrones de comportamiento desarrollados desde la Ingeniería de software para el diseño del Perfil de Usuario. La información sobre sí mismo que el usuario selecciona, inscribe, redacta, comenta, está allí escrita de acuerdo a pautas como: Memento Observer, State, Strategy, Template Method, Visitor...

El empleo que el usuario de una red social hace de estos patrones de comportamiento o protocolos de comunicación, podría ser también una analogía a las estrategias que un actor utiliza para crear su personaje. El uso de esas tecnologías de la computación es el Stanislavsky de la era digital. "No te creo. No me convences". El actor cree ciegamente en la verdad ficticia de su personaje y la vive sinceramente. Confusión en la red: ¿el Perfil de Usuario es el usuario? ¿Quién es el actor-Usuario? ¿Qué es el personaje? ¿Qué es "quién”? El objeto virtual Perfil de Usuario es un ejemplo de cómo una historia de vida de un sujeto de experiencias puede reducirse a la organización de un discurso hipertextual titulado "Proyecto de Vida". De hecho, el protocolo IP del Perfil de Usuario de Facebook es parte de los requisitos que desde hace algún tiempo se anexa a la información de las Hojas de Vida y los Curriculum Vitae. ¿Por qué? Tres razones: primero, el método basado en el auto-reconocimiento un tanto superficial y mecánico que responda a una de las tres preguntas fundamentales de la vida, “QQuién soy?”, resuelve el asunto "quién se cree él/ ella"; segundo, el registro automático de las acciones ejecutadas por el individuo semeja los recorridos transitados, el encadenamiento de acontecimientos que constituyen la trama de una existencia; tercero, el conjunto de datos albergados en la cuenta del usuario ofrece pistas que sugieren a los psico-sociólogos cuál es la repercusión que esos acontecimientos provocan en el sujeto. 
Ahora bien. Si la virtualización es el primer nivel del proceso de conversión de la identidad personal del Usuario a objeto virtual, el segundo nivel del proceso sucede en continuidad con el anterior: la actualización, esto es, la identificación del Usuario con su objeto virtual "identidad-avatar" o personaje central de la ficción histórica escrita en co-autoría con los otros usuarios albergados en la lista de "amigos" del Perfil de Usuario. Esta identificación con un objeto virtual está relacionada con el paso de una narración offline a una online en la red social Facebook. El Usuario, cuyas características personales están siempre en potencia, transforma su sí mismo en un objeto virtual que se actualiza no sólo a través del proceso de modelización de la «identidad avatar» sino durante la interacción con otros usuarios.

\section{Interacción: hay pequeños dioses por todas partes}

Las investigaciones en realidad virtual están, por tanto, particularmente interesadas en las interfaces hombre/máquina. La Interacción es el segundo elemento clave de la realidad virtual. Pero el usuario no se contenta con actuar sobre el programa, sino que está completamente inmerso en la realidad artificial. (...) Esa inmersión es tanto más fuerte cuando que están movilizados todos los sentidos del usuario. (...) el medio ambiente virtual en el que se desarrolla la interacción puede ser local o en red, y en este último caso pueden estar también asociados a la acción de otros seres humanos. (Flichy, 2003:179).

Toda representación virtual digital, toda simulación de una presencia, opera con referentes del mundo real. Simular una presencia implica la representación de un "ser que está ahí". Pero el "estar ahí" en un mundo virtual, implica a su vez que no se está en un sólo lugar sino en muchos. Y, además, que se está acompañado de semejantes, que se interactúa con ellos.

Sherry Turkle en "La vida en la pantalla. La construcción de la identidad en la era del internet" (1995) -hoy en día un clásico en la materia-, comenta que los juegos de realidad virtual son importantes para el ser humano pues, además de desarrollar su creatividad, le permite exteriorizar aquellas ideas y sentimientos que en la vida cotidiana "real" no se consiente. Sin embargo, a pesar de que los hombres son diferentes a las máquinas en tanto tienen sentimientos, mente e intelecto, las personas juegan con las máquinas como si éstas tuvieran vida propia. Ellos las animan.

Hoy más que nunca difuminamos la línea entre la simulación y la realidad, entre lo que existe en un ordenador y lo que es real. Sin embargo, normalmente somos conscientes de que las imágenes y las representaciones en una pantalla no están en el mundo de la misma forma en que estamos nosotros. Aunque la vida artificial creada en el ordenador desafíe nuestro conocimiento de los procesos vivos, todavía es posible trazar la línea entre nosotros (las personas, los animales, los insectos «reales») y ellos (los productos de la vida artificial), al decir que ellos están dentro de aquello (el ordenador) y nosotros estamos aquí afuera, en el mundo. (Turkle, 1995:209).

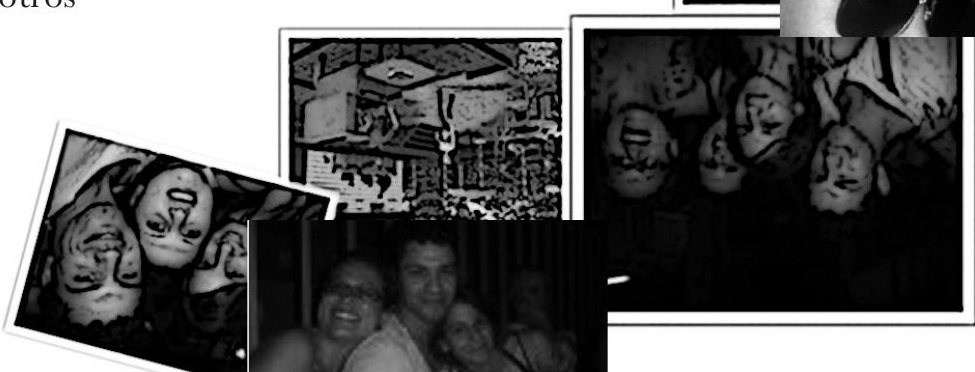


Los juegos de rol ofrecen personajes que se pueden convertir en vidas paralelas. Turkle analiza la interacción entre usuarios de MUD, -videojuego de rol ejecutado en línea desde un servidor de Internet-, espacios de socialización anónima en el que los usuarios crean personajes virtuales con un complejo desarrollo de emociones internas y se adentran en esos mundos a través de herramientas de texto para conversar unos con otros, intercambiar gestos, expresar emociones, ganar y perder dinero y subir o bajar de estatus social (Turkle, 1995:233). El análisis de Turkle -seudónimo de Abby Rockefeller Mauzé, profesora de Social Studies of Science and Technology del MIT-, sugiere que en la realidad, en éste espacio de carne y hueso, somos identidades únicas y no hay otros cambios. Turkle afirma que cuando se juega en Internet se proyecta la identidad propia o lo que se anhela ser.

La noción «eres lo que pretendas ser» tiene un eco mítico. La historia de Pigmalión perdura porque habla de una fantasía poderosa: no estamos limitados
Esa posibilidad de autotransformación surge en los mundos virtuales porque confluyen las diferencias entre el hombre y la máquina -en este caso el hardware informático-: una, que es precisamente esa habilidad de proyección innata en el ser humano la que permite a los usuarios recrear múltiples identidades en Internet; otra, que la «realidad virtual» de Internet no concibe parámetros sociales o éticos y morales, situación que facilita la desinhibición del miedo a ser juzgado. El anonimato es una estrategia de juego.

En esa línea de pensamientos, el análisis del discurso de la profesora Hine (2000) -los grupos de noticias en relación al juicio mediático de la niñera Louise Woodward-advierte que las nuevas tecnologías de las $\mathrm{CMO}$ introducen problemas fundamentales para distinguir lo auténtico de lo falso. Para Hine, el asunto de la autenticidad de la información en Internet se basa en la confianza, pues nada garantiza que una identidad en el ciberespacio refleje lo que es una persona en su vida offline -fuera de la pantalla- ya que, en general, el usuario aprovecha su anonimato en los espacios online para jugar diferentes roles y personalidades.

La relevancia de las afirmaciones o descripciones expuestas en estos espacios podían ser objeto de discusión, pero la validez de la identidad, rara vez era atacada. Cabe pensar que los participantes simplemente no cuentan con recursos suficientes como para rebatir convincentemente una identidad. Alternativamente, podríamos pensar que la identidad no es pertinente a las discusiones en la mayoría de los casos o, dicho de otro modo, que no importa si alguien es "en verdad" quien dice ser. Las identidades se aceptan tal como se manifiestan siempre que confiar no implique riesgos. No se trata de una ingenuidad o credulidad sino de una confianza situada, que depende de lo que se pone en juego cuando se acepta, sin reservas, una declaración de identidad. (Hine, 2004: 176,177). 
En ese sentido, la simulación de una identidad personal en Internet es también una cuestión ética: allá, los usuarios son libres de actuar según sus pasiones y emociones sin retroalimentar sus experiencias con las consecuencias que tal vez sí tendrían en el mundo real -"Nosotros luchamos para liberar la información. Nosotros combatimos por la libertad de expresión y de prensa. Por la libertad de expresar nuestros pensamientos libremente, sin ser perseguidos por el Sistema"(Manifiesto Cyberpunk)-; acullá, exacerban sus imaginerías, fantasean con sus deseos y anhelos y, en la mayoría de los casos, se "dejan llevar" por el instinto tal como los hombres que se satisfacen con las sombras de la caverna platónica.

Este podría ser el caso de las redes sociales, espacios virtuales de interacción en el que se conjugan el patrón de comportamiento de una identidad personal y el carácter de autenticidad del objeto virtual "perfil de usuario". La íntima relación entre la vida offline y online del usuario mantiene su continuidad en la metáfora de la realidad que es el ciberespacio pues, por una parte, la autenticidad de la información albergada en el perfil de usuario siempre tendrá un referente real tomado del sujeto que actúa como usuario; y por otra, sabe también que los actos y decisiones que tome como usuario no afectarán su vida como sujeto (por ejemplo, borrar el perfil de usuario no indica su muerte inminente). Si ese referente a la realidad se perdiera, arrastrando consigo el voto de confianza en el Otro, el mundo virtual sería un caos de ideas y de pensamientos; de incertidumbres. Y, en la práctica cotidiana no lo es -aún-: ahí se mantiene un orden similar al de este mundo real.

Quiero decir: lo que aquí se proyectaba mentalmente, lo que se vivía en el hábitat terrestre como metáfora ahora es proyectado, sin la menor metáfora, en el espacio absoluto, el de la simulación. (Baudrillard, 1988:13).

\section{La imagen del Perfil de Usuario}

Aprender agrada muchísimo no sólo a los filósofos sino igualmente a los demás, aunque lo compartan escasamente. Por eso, en efecto, disfrutan viendo las imágenes pues sucede que, al contemplarlas, aprenden y deducen qué es cada cosa, por ejemplo, que éste es aquél; pues, si uno no ha visto nunca al retratado, no producirá placer como imitación, sino por la ejecución, o por el color, o por alguna causa semejante.

\section{Aristóteles, "Poética", IV}

Dice la antigua filosofía egipcia que cuando morimos perdemos 21 gramos. Ni siquiera una imagen digital de nosotros mismos pesa tan poco. Para ser exactos: no pesa nada. Pero ocupa espacio. En la avenida de la información, un sistema circulatorio de bits, la imagen digital tampoco tiene la apariencia que vemos en la pantalla del computador. No se asemeja ni imita ningún objeto. Compuesta desde el sistema binario, la «imagen digital» es una representación de información: agrupaciones de ocho pulsos electrónicos, bytes, números uno y cero, en diferentes posiciones. 1 y 0. Encendido y apagado. Presencia y ausencia. "La información es energía pura", escribía McLuhan. A través de la electricidad todos los medios de comunicación pueden ser contenidos, transformando los mensajes en impulsos electrónicos.

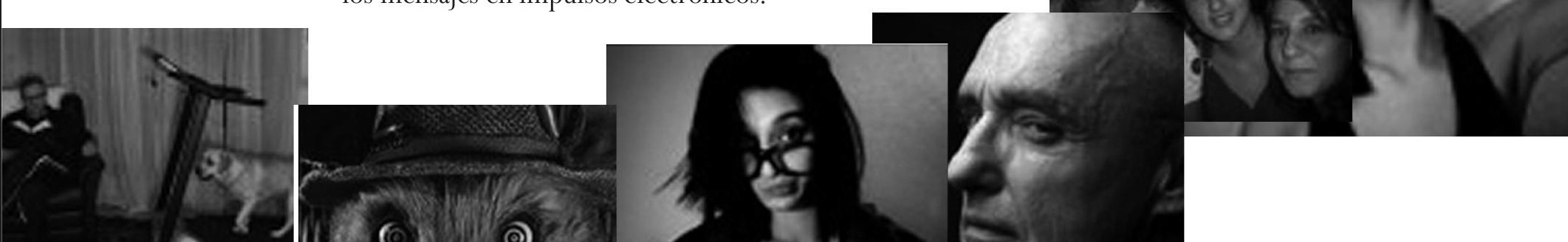


En Internet, cuando una «imagen digital» es llamada por un usuario, esos impulsos electrónicos viajan por la red hasta llegar a un enrutador ${ }^{10}$ ubicado en la oficina del proveedor de servicios. Luego de haberse establecido un canal de comunicación entre el usuario y la imagen solicitada, la información almacenada en el Servidor inicia su proceso: desde una gran máquina de operaciones, un más allá electrónico, el mensaje que el usuario ha enviado solicitando la imagen es respondido con un nuevo envío de impulsos electrónicos. Luego, esos bytes llegan hasta allí, su software, para acumularse en un archivo: descarga de información. Es entonces, desde un archivo del computador, que vemos la imagen digital en la pantalla. Mientras esa imagen digital que representa la presencia de sí mismo en alguna parte, no esté ni allá ni allí, quiere decir que está en el limbo. Y en el limbo, esos 21 gramos de energía se conservarán hasta el fin de la era electrónica.

La imagen digital reafirma, en nuestra era de los objetos sensibles de la RV, el carácter de "autenticidad" de la información allí expuesta en el Perfil de Usuario. En ese sentido, el segundo nodo de ideas:

La imagen no simula una presencia sino que es la presencia misma del Usuario. La imagen es el alma del objeto virtual Perfil de Usuario.

En nuestra época de sistemas electrónicos de información, la imitación no es sólo una representación de objetos reales desde una perspectiva icónica, propia a lo analógico. También es una re-creación de objetos que existen en el mundo no virtual: por una parte, imaginería, fantasía, ciencia ficción, diseño digital, son los contextos de las obras; por otra, los temas no son representaciones de la naturaleza que se exhiben ante el espectador de modo que él deba completar el sentido de la obra. En algunas ocasiones, la lusus naturae - la ilusión en las formas de la naturaleza- en una imagen digital carece de objeto referenciado: son imágenes que no imitan, que no se parecen a nada que, conscientemente, se haya visto antes.
Los referentes del objeto están en las mentes del autor y del espectador. Son sus recuerdos los que proyectan en la pantalla.

Por ejemplo, en la obra fílmica "The Mirror Mask" (UK, 2005), el ilustrador y director Dave McKean ofrece al espectador imágenes fascinantes de difícil remembranza con otros ya vistos -por lo menos en el mundo real-. Su historia repite la metáfora dantesca de la búsqueda que un alma debe realizar para liberarse de la personalidad que la aprisiona: Helena es una adolescente de quince años que encuentra en sus dibujos una salida hacia el mundo del espejo -un mundo virtual-, recreado por recuerdos bizarros de sus propias historias familiares.

Allí, ella, su alma, es una princesa encarcelada por las acciones de su rebelde personalidad: cuando mira ese mundo real por una ventana, se da cuenta cómo su carcelera se transforma en una joven aún más irascible y voluntariosa.

La propuesta escénica de McKean, diseñada digitalmente, incluye, además de pequeños monstruos que los espectadores podemos reconocer por algunos rasgos físicos -gatos esfinge y pájaros gorila- y de decorados angustiosos y absurdos como escaleras en forma de caracol que concluyen en ninguna parte -semejantes a las Prisons de Piranesi-, imágenes de seres animados como aquellos de extremidades largas y cuerpos ovalados sin cabezas que hablaban no sabemos por dónde pero que hacían referencia a un grupo de soldados. 
En "The Mirror Mask" un espectador que desconoce el referente de "Alicia en el Espejo” de L. Carroll, podría sentir este tipo de placer por la forma y la técnica. Y si siente fascinación por ella porque es nueva, porque no la ha identificado con el objeto imitado, no hay en él comprensión ni deducción del objeto representado. Por el contrario, si reconoce el objeto imitado es porque ha evocado el recuerdo de un objeto ya visto. Su recuerdo se ha identificado con el recuerdo del autor. Lo que quiere decir que el espectador es co-autor de la obra; él la completa desde el momento en que la interpreta.

Para E.H. Gombrich (Arte e Ilusión, 1960) este proceso psicológico de dar forma y sentido a la imagen, corresponde a uno de los métodos que emplean los artistas cuando evocan en un objeto una presencia sugestiva: el principio de proyección: la "significación -del «objeto encontrado»- no aparece sino hasta cuando alineamos el estado de espíritu del espectador". Es decir, el espectador ve en la obra la representación de sus recuerdos visuales. Ve lo que puede -y quiere- ver, como los pacientes de Roschard, como los enfermos de Arkham Asylum, como los Usuarios de Facebook.

...Tecnologías delYo, que permiten a los individuos efectuar, por cuenta propia o con la ayuda de otros, cierto número de operaciones sobre su cuerpo y su alma, pensamientos, conducta, o cualquier forma de ser, obteniendo así una transformación de sí mismos con el fin de alcanzar cierto estado de felicidad, pureza, sabiduría o inmortalidad (Foucault, 2002:48)

En un mundo virtual, la realidad no es lo que está en juego. Tampoco la certeza de autenticidad del objeto virtual que allí simula al usuario. Sin embargo, el Perfil de Usuario si tiene algo de neurótico: ¿hace parte de una realidad ignorada por el usuario? ¿Por qué nos fascina? ¿Es una cosa idéntica o semejante a un "Yo"? ¿Qué debemos comprender por "Yo"? En sus Seminarios de los años 1954 y 1955 Lacan describió la cuestión del Yo como una función imaginaria que opera en relación con las otras funciones, simbólica y real, integradoras de la totalidad.

Dicho de otro modo: todo está relacionado. Para entender lo que sucede en el dominio propio del orden humano, tenemos que partir de la idea de que este orden constituye una totalidad. La totalidad en el orden simbólico se llama universo. (Miller, 1977:50).

Siguiendo las reflexiones de Freud sobre el proceso onírico y el inconsciente, esbozó también la distinción entre el yo (je $)^{11}$-el sujeto, el que hace- y el yo -el individuo-. Advirtió a su auditorio que muchos analíticos han hecho coincidir el sujeto con el individuo en un intento de volver al equilibrio resquebrajado por esa dialéctica. Lacan explicó entonces al yo, al individuo, como "literalmente, un objeto que cumple una determinada función que aquí denominamos imaginaria"l2. Y dijo del yo (je), el sujeto, que es -en palabras de Freud- el núcleo central de nuestro ser; el inconsciente ignorado por el individuo: un núcleo ontológico, excéntrico, que no se ubica fácilmente en el sistema de la conciencia ${ }^{13}$. 


\section{La Identidad-Avatar: Perfil de Usuario + Imagen}

(...) Tu avatar puede tener el aspecto que desees, según las limitaciones de tu equipo. Si eres feo, puedes hacer que tu avatar sea atractivo. Aunque acabes de salir de la cama, tu avatar puede lucir ropas hermosas y un maquillaje profesional. En el Metaverso puedes ser un gorila o un dragón o un enorme pene parlante. Si recorres el Metaverso durante cinco minutos verás ejemplos de todas esas cosas.

(...) No puedes materializarte en el Metaverso donde quieras, como el capitán Kirk teletransportándose desde las alturas. Provocaría confusión y molestaría al resto de la gente; rompería la metáfora. Se considera que materializarse saliendo de ninguna parte (o desvanecerse de vuelta a la Realidad) es un asunto privado, y que es mejor realizarlo en Casa. Hoy día, casi todos los avatares son anatómicamente correctos y se crean desnudos como un niño, así que hay que adecentarse antes de salir a la Calle. Salvo que tu avatar sea intrínsecamente indecente y no te importe.

Snow Crash, 1995:25

Neal STEPHENSON

Todos los hombres desean saber. El saber se da gradualmente por los sentidos, las percepciones. Así, el saber de la memoria -los recuerdos- privilegia el sentido de la vista $y$, sobre los recuerdos, se forma la experiencia que luego pasa a ser una regla práctica -techne. ¿Cómo se da este paso de experiencia a regla práctica? A través del lenguaje que permite traducir y transmitir esa experiencia. Pensar el «ser»se hace desde el lenguaje.

¿Qué significa «conocer»? Si las personas no tienen ciertas potencias en el alma, no podrían aprender ciertas cosas. El proceso de conocimiento inicia con la sensación; luego pasa a la imaginación; de ahí a la generación de memoria; y, finalmente, se recuerda la experiencia. Es desde la experiencia que es posible hablar de modos de aprendizaje en las ciencias. Para Aristóteles, el «movimiento» es el tránsito de la potencia al acto. De ahí que, en el alma, se está dando un movimiento cuando de no conocer algo se pasa a saber algo.

El diseño digital de una imagen virtual que represente la identidad personal demuestra que la facultad de creación, de transformación, de reinvención de sí mismo, opera también en otro espacio diferente al de los objetos reales. En estos lugares que son los «mundos virtuales», la percepción de sí mismo a través de lo visual -principalmente- es, para el usuario de internet, otra forma de experimentar lo "real" de su permanencia espacio-temporal. - Comprender qué es lo virtual es preguntarse por el significado de lo real. No podría ser de otra manera: lo virtual y lo real son características, propiedades o determinaciones que constituyen aquello que el sujeto interpreta como la realidad, esto es, aclarémoslo de entrada, su visión -decible- del mundo, el

Weltanschauung expresado por Dilthey. En ese sentido, comprender los procesos de auto-reafirmación de la identidad personal en el mundo, en este caso, un mundo virtual, implica revisar el

concepto «identidad personal» (I) como entidad, objeto de representaciones diversas; (II) como actualización, solución o respuesta al problema que plantea su temporalidad; y (III) como virtualización o campo problemático de la respuesta. 
En una plataforma interactiva, «avatar» es el nombre que recibe la "persona en 2D o 3D" que representa la identidad personal de un sujeto-usuario inscrito en una red social. El escritor norteamericano Neal Stephenson es un referente obligado de la corriente Cyberpunk pues ha sido el primer autor en describir el modus operandi de los avatares en el Metaverso -o Ciberespacio, término con el que se conoce esta realidad virtual popularizada por William Gibson en su novela Neuromancer ${ }^{16} \mathrm{y}$ a la que John Perry Barlow, miembro de la International Academy of Digital Arts and Sciences, ensalzó en la Declaración de Independencia del Ciberespacio:

Debemos declarar nuestros "yos" virtuales inmunes a vuestra soberanía, aunque continuemos consintiendo vuestro poder sobre nuestros cuerpos. Nos extenderemos a través del planeta para que nadie pueda encarcelar nuestros pensamientos. Crearemos una civilización de la Mente en el Ciberespacio. Que sea más humana y hermosa que el mundo que vuestros gobiernos han creado antes.

Volvemos así a la materialización del viejo deseo platónico: el «avatar», en sánscrito avatara, significa “descenso", la encarnación de los dioses en el mundo de los hombres. Los cuentos hindúes hablan del deseo divino de «hacerse otros» cuando en realidad es Él mismo con sus otros rostros. El Âtman en su septuplicidad. "Veo en tu cuerpo universal, innumerables formas, ojos, bocas, brazos y vientres, dirigidos a todas partes con una forma infinita”. Una de las cualidades de los avatares es que conservan su naturaleza divina y sabiduría que les permite no participar de las emociones ni deseos -debilidades- humanas. En las revistas de ciencia y tecnología que tratan asuntos sobre ciberespacio, internet y videojuegos, el avatar, por ejemplo en el juego de roles de Second Life, es el nombre que reciben las "personas en $3 \mathrm{D}$ ” que lo representan en esa plataforma interactiva. La otra personalidad. Una que es tal cual como se desea ser y que no se es en este mundo real: “¿Quiere conocer gente? Es lo más fácil, barato y cotidiano en este mundo virtual. Sin tener que pagar un peso -o en este caso un dólar-, puede llevar a su personaje a caminar o ponerlo a volar hasta que encuentre otro avatar”18

El avatar es también una de las representaciones de nuestra personalidad. La identidad-avatar en el ciberespacio de Facebook -ligeramente menos hermoso de lo esperado...comienza cuando el jugador se configura como personaje, como avatar -a este proceso lo denominaremos en adelante "podría ser”-. El jugador podría ser mujer, si es hombre. Podría ser una prostituta si es una ama de casa. Podría ser un asesino en serie si es una eminencia de la medicina al que lo agobia la condición humana. Podría ser lo que desee, que no deseará ser más allá de lo que se imagina, de lo que es. Las posibilidades de «ser» en un mundo virtual, la potencia de lo que ya es en su cotidianidad, son sólo proyecciones. Abro un paréntesis: la mitología ofrece también sus ejemplos. Si la bella Gorgona mortal Medusa, con su cabellera de serpientes, fuera una representación de los pensamientos del sublime héroe Perseo, bien que quisiera él asesinarla al descubrir quién es él, quién es ella: ora un semidios hijo de Zeus, ora un terrorífico monstruo.

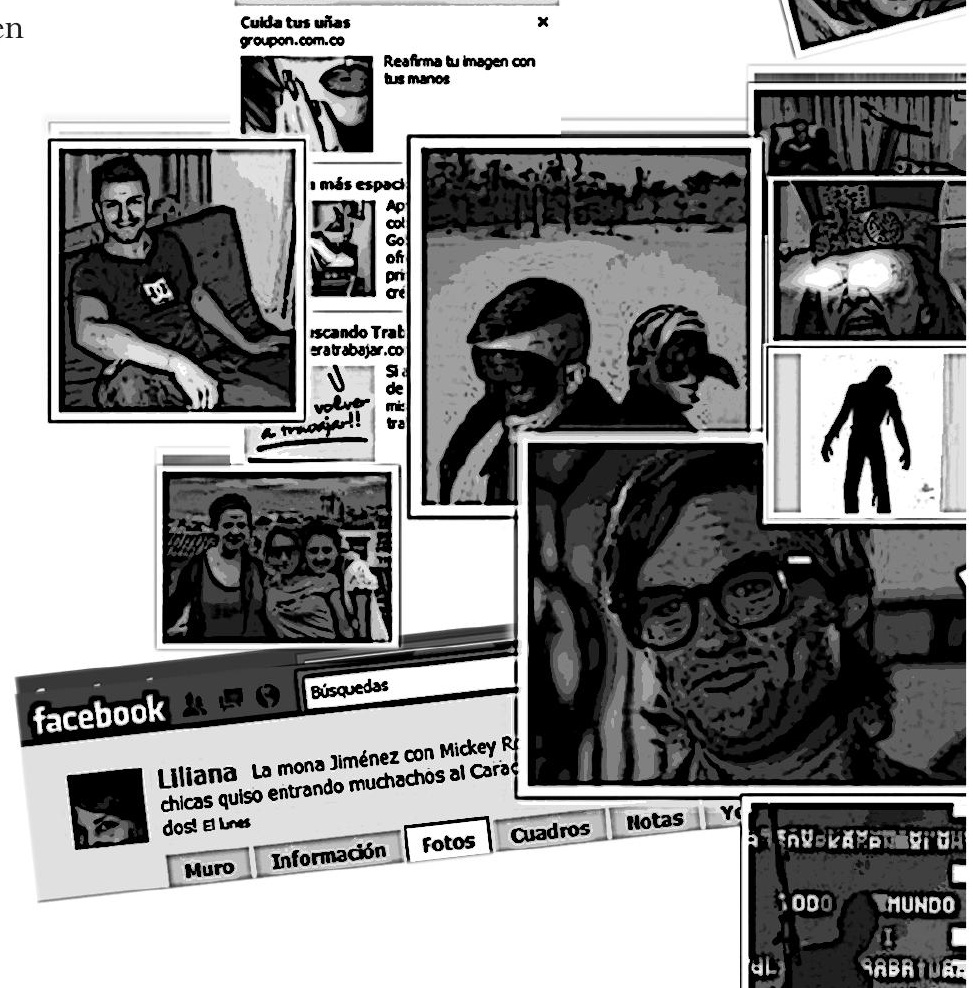


El escudo reflector, regalo de Atenea, le serviría de espejo de su sí mismo. La Medusa es la proyección de una parte de la personalidad de Perseo, de lo que podría ser. Cierro el paréntesis.

Ejemplos de este ejercicio de conocimiento de sí mismo con ayuda de la tecnología que "salvaría al psicoanálisis del mundo real", como cuestiona Stallabrass, hay muchos. En el mundo de las artes digitales, de la ciencia y la tecnología, de las redes sociales que se entretejen en el ciberespacio, los encontramos frecuentemente.

\section{Apuntes finales}

La experiencia de lectura de un "Perfil de Usuario" incluye también la interpretación de la semiótica de los iconos-hipervínculos. Pero este ejercicio interpretativo ha estado siempre presente en el estudio de cualquier texto escrito. No obstante en las nuevas tecnologías de la comunicación - ¿hasta cuándo se les seguirá llamando nuevas?- como Internet, la navegación en la realidad virtual ofrece la experticia básica en software para el manejo de las herramientas de programación, por ejemplo, las aplicaciones de la red social. No es indispensable entonces que un Usuario de la Red sea ingeniero o matemático para aprender a configurar su Perfil. La tecnología Internet -en paralelo con las otras tecnologías de la imagen como el cine y la televisión- conlleva a una nueva alfabetización de la palabra que implica el aprendizaje de nuevos modos de narrar y leer las memorias de vida de otros usuarios.

Internet es, por tanto, otro componente de la cultura informática que ha contribuido en la reflexión de los modos de comunicación, el espacio-tiempo, la organización social y, en nuestro caso particular, en la identidad personal-avatar en términos de multiplicidad del sí mismo. Si el Perfil de Usuario es el objeto virtual que simula una presencia que es representada por una lista de datos, agrupaciones de imágenes y comentarios de otros usuarios, es la palabra escrita -otro

objeto virtual- el lugar en el que converge la búsqueda de sí mismo: el deseo del Usuario de extenderse a través del tiempo y del espacio -trascender-; el deseo de estar en todas partes -ubicuidad-; el deseo de ser visto y reconocido, de quedar en la memoria -inmanencia-. Rodríguez de las Heras tal vez dirá que estos mismos deseos de los hombres han estado implicados, desde siempre, en el uso de la palabra escrita.

La identidad-avatar es una proyección de la imagen que de sí mismo el Usuario ha creado a partir del significado que le otorga a sus recuerdos y a su forma de ser, a su carácter: esa imagen es un representarse más allá. Es trascender, un extenderse hacia un más allá del mundo real. El Usuario es como un punto imperceptible en la línea de los acontecimientos. La lectura de los comentarios y actividades en la página "Inicio" y "Muro" de su Perfil de Usuario en Facebook es como un trazo que se inicia. El punto final no es el mismo del principio.

El recorrido de puntos es una continuidad, un desplazamiento. La inmersión en su Perfil no causó una transformación en su existencia como punto. No hubo un cambio ni de tono, color, tamaño. Pero es innegable: su relación con el exterior, la percepción que tiene de sí mismo se alteró. El Usuario, revestido en el objeto virtual Perfil de Usuario, se ha actualizado. 
Ha sido taggeado. Podría ser que el mundo virtual sea el lugar donde se manifiestan los procesos de «descenso» de nuestra conciencia personal en múltiples formas virtuales: el ejercicio de desplazar el sentido que tenemos de sí-mismo en este mundo, hacia otro mundo. Una proyección en una simulación.

Óscar Wilde ha escrito: "Hay dos tragedias en el hombre: no alcanzar lo que desea y alcanzar lo que desea". La realidad del sujeto es una realidad psíquica: consiste en hacer que el juego del placer dure, se renueve.

¿Qué es el placer? Freud decía que lo encontrábamos en la estimulación del sistema nervioso. Esto es en la emoción. En la libido. En el olvido momentáneo de sí mismo. En la sensación embriagadora y pacificadora de no estar ahí en el cuerpo: una sensación que, según como sea percibida, tiene una duración específica.
El principio de realidad consiste en hacer preservar ese placer. La realidad no es más que un pasado rememorado del objeto que ya no está. Esa desaparición del objeto sucede ante nosotros en un instante. El instinto de muerte, tema del Entwurf (Freud, 1985), se activa una vez que esa desaparición nos vuelve buscadores de su imagen en nuestra conciencia, en nuestro universo de objetos llamados a través de signos y símbolos. "El recuerdo - anotaba Plotino-es para los que han olvidado" 19 .

¿Un ejemplo de esta función sensorial del deseo y el placer? El avatar: la imagen narcisista. La cosa que el sujeto construye a través de un simulador de RV en esa otra naturaleza de la realidad objetiva.

Marshall McLuhan consideraba la tecnología como una extensión del cuerpo. También lo es de la psique humana. La actividad de una identidad avatar en el ciberespacio es expansión de las posibilidades adquisitorias en una sociedad definida por el consumo.

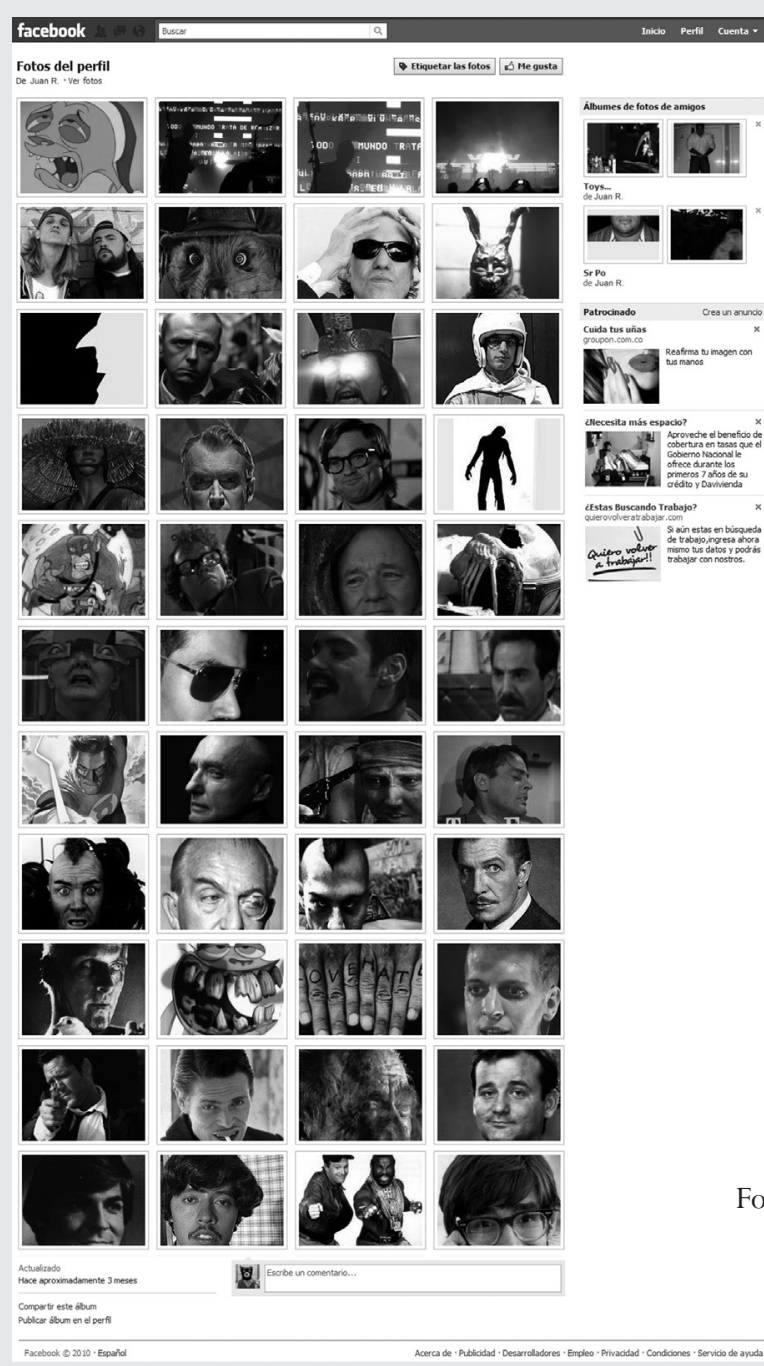

\section{ANEXOS}

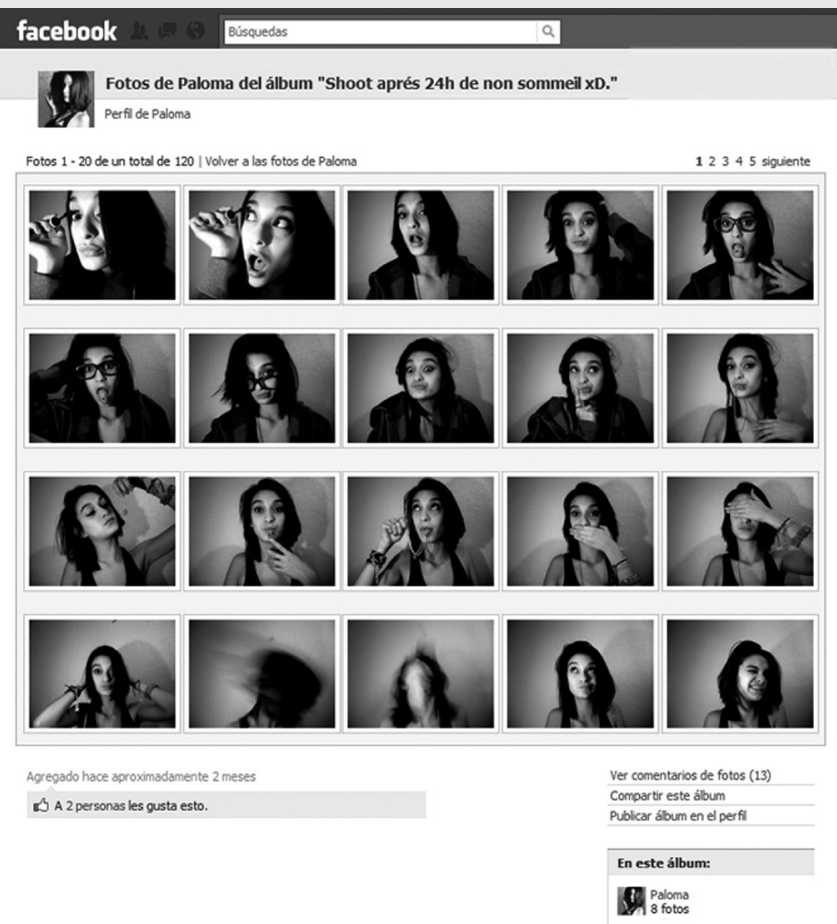

Fotos del Álbum de Perfil de Usuario "Paloma". 


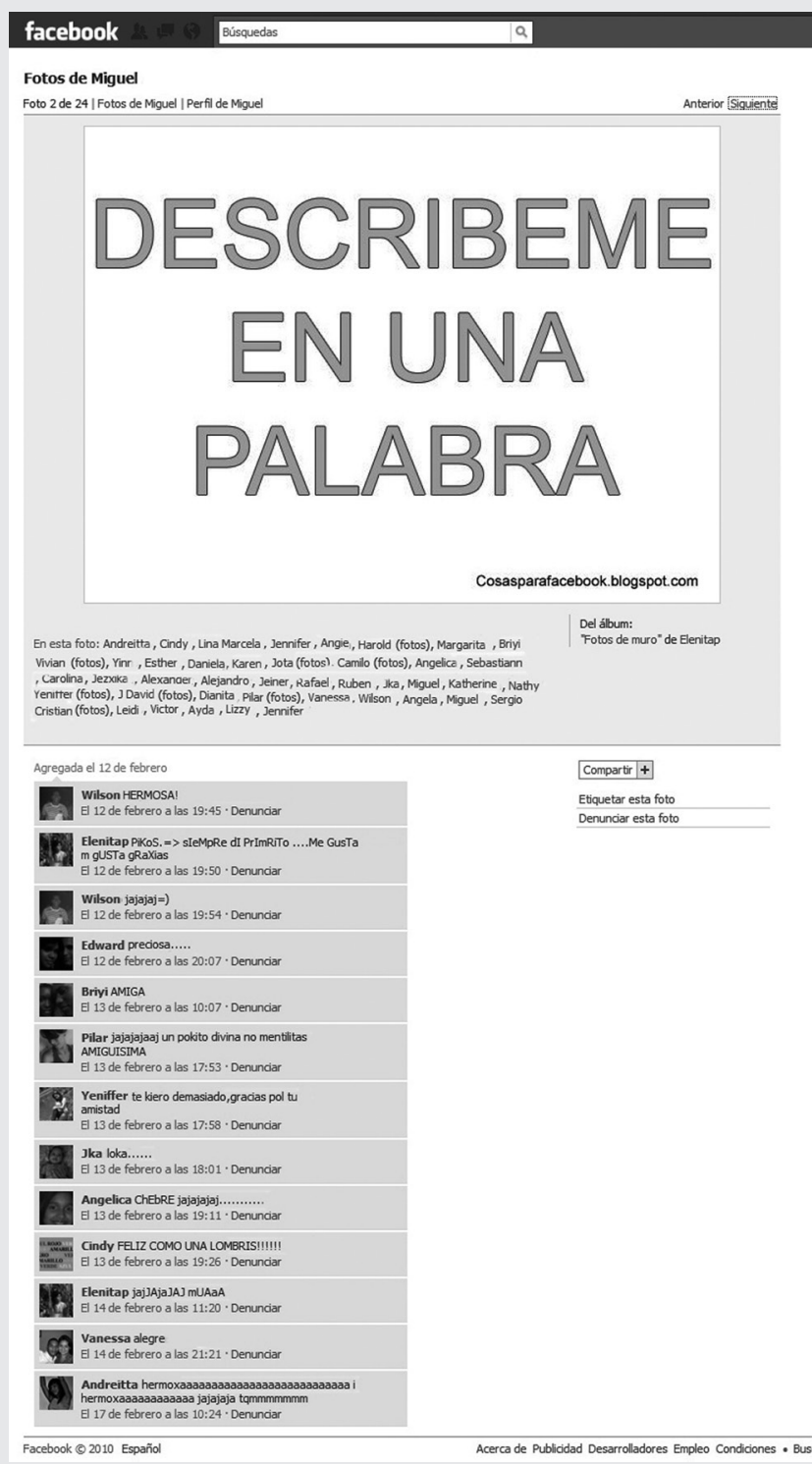

Fotos del Álbum de Perfil de Usuario "Miguel”.

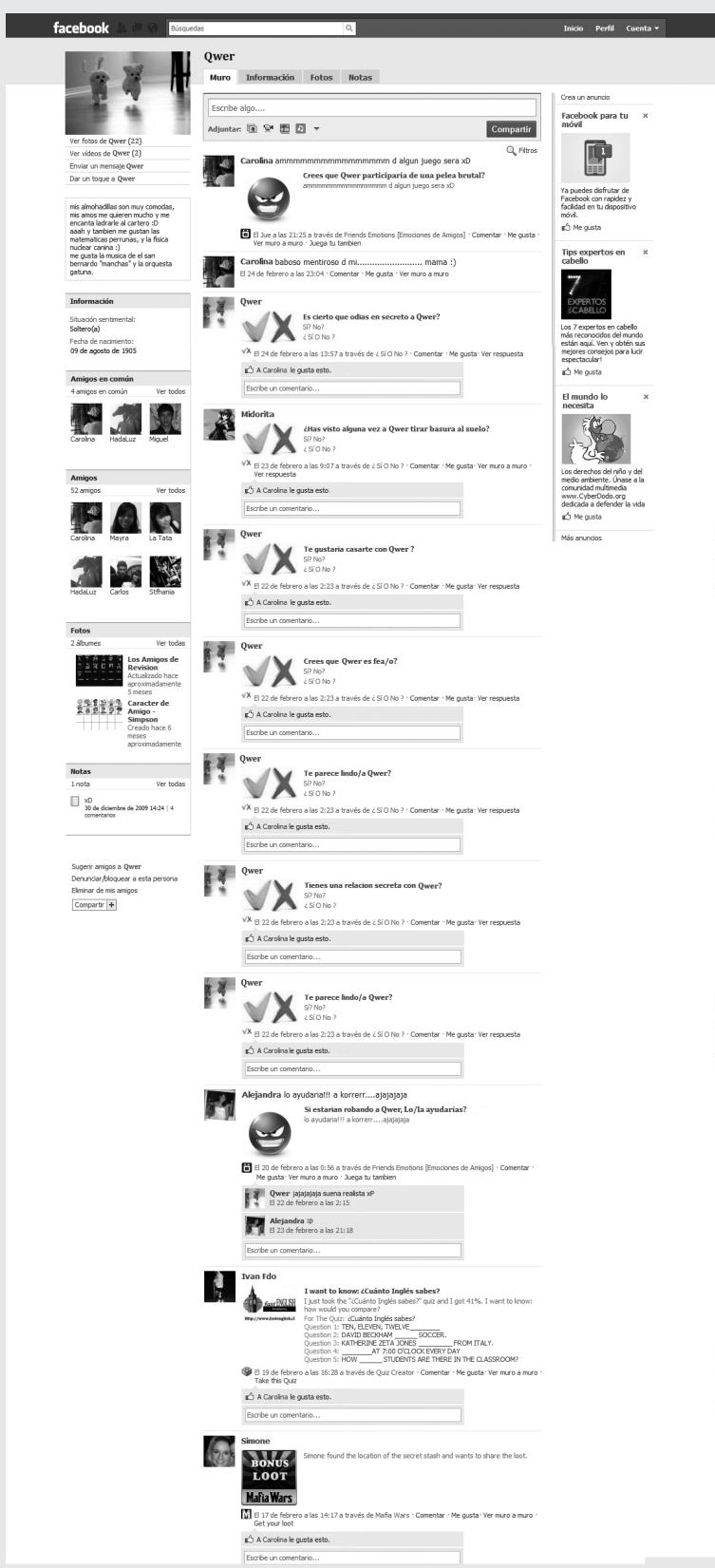

Muro de Perfil de Usuario "Qwer". 


\section{Notas}

1 El presente artículo hace parte de la tesis de grado para optar por el título de Maestría en Filosofía de la Universidad del Valle. "Juegos de Identidad en los Mundos Virtuales: Ia Identidad-Avatar" (2011).

2 Comunicadora Social y Maestra en Filosofía de la Universidad del Valle. Profesora en los Departamentos de Español y de Estudios Políticos de la Universidad Icesi, y miembro del grupo de trabajo Área de Ciencia, Tecnología y Sociedad. E-mail: andrea_ rm@hotmail.com / Cel: 3104330580.

3 J.P. Vernat. La mort dans les yeux. Paris, Hachette.

4 Referencia a las Multitudes Inteligentes de Rheingold.

5 No está de más decir que ésta película es una proyección de los polémicos avances científico-tecnológicos en nanotecnología que actualmente se desarrollan en el campo de la medicina, la biología, el medioambiente, la inteligencia artificial y la informática; en estos dos últimos en materia de nanorobots y autoreplicación.

6 Rheingold, uno de los primeros teóricos que hace referencia a la RV, plantea que la relación hombre-tecnología, producto de la revolución digital, conlleva a nuevas formas de sensibilización de los objetos virtuales. En esa línea, prevé que las aplicaciones futuras de la RV deberán incluir el sentido del tacto. Actualmente la relación usuario-touchpad hace parte de la vida cotidiana.

7 Maldonado, T. (2004). Mundo Virtual y Mundo Real. Tomado de la Revista Debats No. 84, Primavera de 2004. Recuperado el 29 de septiembre de 2011, en http:/ / www.alfonselmagnanim.com/DEBATS/84/espais03.htm

8 Un aspecto que considero podría desarrollarse más adelante es la cuestión de los modos de escritura y lectura de la información alojada en Internet a modo de hipertexto. Al respecto, cito de Lévy un párrafo que podría aportar significativamente como punto de partida en posteriores investigaciones:

Actualmente, la interpretación, es decir la producción de sentido, ya no remite exclusivamente a la interioridad de una intención, ni a jerarquías de significaciones esotéricas, sino a la apropiación, siempre singular, de un navegador o un surfista. El sentido emerge de los efectos locales de pertinencia, surge en la intersección de un plano semiótico desterritorializado y de un propósito de eficacia o de placer. Ya no me intereso en lo que ha pensado una autor ilocalizable, sino que le pido al texto que me haga pensar, aquí y ahora. La virtualidad del texto, de hecho, alimenta mi inteligencia. (Lévy, P. ¿Qué es lo virtual?, p.47).

9 Carrol, L. (2003). Cap. VI. Humpty Dumpty. En Alicia en el Espejo. Trad. Luis Maristany. Plaza y Janés, Barcelona, p. 189.

10 De la palabra anglosajona «Router»: tipo de dispositivo de internetworking que pasa paquetes de datos entre redes basándose en direcciones IP. Un router puede tomar decisiones acerca de la mejor ruta para la distribución de datos por la red. (Tomado de Guía del primer año de Cisco Certified Networking Associate, editorial Pearson Educación S.A. Madrid, 2004).

11 En francés, je acompaña la conjugación del verbo: es el sujeto que ejecuta la acción.

12 Miller, J. A. El Seminario de Jacques Lacan. Libro 2: el yo en la teoría de Freud y en la técnica psicoanalítica. Ibíd., p.73.

13 "La conciencia es algo que se produce cada vez que tenemos una superficie tal que pueda producir lo que llamamos una imagen. Es una definición materialista”. Ibíd., Miller, pág. 80.

14 Miller, J. A. El Seminario de Jacques Lacan. Libro 2: el yo en la teoría de Freud y en la técnica psicoanalítica. Ibíd., p. 50. 15 Op.cit. p.58-60.

16 Gibson, William (1984). Neuromancer, "El ciberespacio. Una alucinación consensual experimentada diariamente por billones de legítimos operadores, en todas las naciones, por niños a quienes se enseña altos conceptos matemáticos... Una representación gráfica de la información abstraída de los bancos de todos los ordenadores del sistema humano. Una complejidad inimaginable. Líneas de luz clasificadas en el no espacio de la mente, conglomerados y constelaciones de información. Como las luces de una ciudad que se aleja...” (p.50).

17 Diálogo entre el príncipe Arjuna y Krishna. Bagavad-Gita, XI-16.

18 Revista Enter 2.0. Edición No. 99 de marzo de 2007.

19 Eneadas, 4, 6, 7 


\section{Referencias}

Aristóteles, Poética, Editorial Gredos, Madrid, 1974.

As. Kirtchev, Christian (1997). Manifesto Cyberpunk. En: Taringa! Inteligencia Colectiva. Recuperado el 29 de septiembre de 2011, en http: / /www.taringa.net/posts/arte/788448/Manifiesto-CyberPunk-\%5Bliteratura\%5D.html

Baudrillard, Jean (1978). Cultura y Simulacro. Trad. por Pedro Rovira. Barcelona, Kairós. (1988) El Otro por Sí Mismo. Barcelona, Anagrama.

Canevacci, Massimo. Etnografía web e identidades avatar. En: Revista Nómadas No. 21, año 2004. Recuperado el 29 de septiembre de 2011, en

http: / / www.ucentral.edu.co/NOMADAS/nunme-ante/21-25/nomadas-21/11-etnograf\%EDa\%20massimo.pdf

Flichy, Patrice (2003). Lo imaginario de Internet. Trad. por Félix de la Fuente Pascual y Mireia de la Fuente Rocafort.

Madrid, Tecnos.

Foucault, Michel (2002). Tecnologías delYo. Trad. por M. Allendesalazar. Paidós, Barcelona.

Gombrich, Ernest H. (2002). L'Art et Ilusion. Psychologie De La Représentation Picturale. Phaidon, Paris.

Gubern, Román (2000). El Eros Electrónico. Madrid, Taurus.

Gordon, Graham (2001). Internet, una Indagación Filosófica. Madrid, Cátedra.

Hine, Christine (2004). Etnografía Virtual. Trad. por Cristian P. Hormazábal. Barcelona, UOC.

Kandel, E.R.; Schwartz, J. H. \& Jessell, T. M. (2003). Neurociencia y Conducta. España, Prentice Hall.

Lévy, Pierre (1999). ¿Qué es lo virtual? Trad. por Diego Levis. Paidós.

Lowe, E. J. (2000) Identidad personal y conocimiento de uno mismo. En: Filosofía de la Mente. Idea Books.

Maldonado, Tomás (1998). Crítica de la Razón Informática. Trad. por Juan Carlos Gentile Vitale. Barcelona, Paidós.

McLuhan, Marshall (1994). Comprender los medios de comunicación. Las extensiones del ser humano, Paidós, Barcelona.

Miller, Jacques-Alain (1997). El Seminario de Jacques Lacan. Libro 2: el yo en la teoría de Freud y en la técnica psicoanalítica. Buenos Aires, Paidós.

Platón. Fedón o del Alma. En Obras Completas, Porrúa, México, 1996.

Propp, Vladimir (1981). Morfología del Cuento. Trad. por Lourdes Ortiz. Madrid, Fundamentos, 5 a edición.

Ricoeur, Paul (2005). Discours et Communication. Paris, L'Herne. (1996). Sí Mismo Como Otro. Madrid, Siglo XXI.

(1990). Soi-Même Comme une Autre. France, Éditions du Seuil.

Rodríguez de las Heras, Antonio (2004). Espacio Digital. Espacio Virtual. En: Revista Debats, Número 84.

Searle John (1994). Mentes, Cerebros y Programas. En: Filosofía de la Inteligencia Artificial. Compilado por Margaret A. Boden.

México, Fondo de Cultura Económica.

Stallabras, Julián (1998, julio-agosto). Formas de Identidad en el Ciberespacio. En Revista de Occidente, No.206.

Turing, Alan (1994). La Maquinaria de Computación y la Inteligencia. En: Filosofía de la Inteligencia Artificial. Compilado por Margaret A. Boden. México, Fondo de Cultura Económica.

Turkle, Sherry (1995). La vida en la pantalla. La construcción de la identidad en la era de internet. Buenos Aires, Paidós. Woolley, Benjamín (1994). El Universo Virtual, Acento Editorial, Madrid.

Recibido: septiembre 15

Aprobado: noviembre 13 de 2011 